Original Article

\title{
Development and evaluation of the sedentary behavior and light-intensity physical activity questionnaire
}

Rumi Tanaka, MS ${ }^{1)}$, Kimie Fujita ${ }^{2)^{*}}$, Kiyoko Makimoto ${ }^{3)}$, Kanako Yakushiji, PhD $^{2)}$, Satomi TanaKa, MS ${ }^{1)}$, Goro Motomura, $\mathrm{PhD}^{4)}$, Masanori FujiI, $\mathrm{PhD}^{4}$, Satoshi Ikemura, $\mathrm{PhD}^{4)}$, Yasuharu NaKashima ${ }^{4)}$

1) Department of Health Sciences, Graduate School of Medical Sciences, Kyushu University: 3-1-1 Maidashi, Higashi-ku, Fukuoka, Japan

2) Division of Health Sciences, Graduate School of Medicine, Kyushu University, Japan

3) Department of Nursing, School of Nursing and Rehabilitation, Konan Women's University, Japan

4) Department of Orthopedic Surgery, Graduate School of Medical Sciences, Kyushu University, Japan

\begin{abstract}
Purpose] To describe our newly developed Sedentary Behavior and Light-Intensity Physical Activity Questionnaire and examine its reliability and validity. [Participants and Methods] We identified and selected self-reported items through a literature review and interviews with 11 inactive individuals. Thirty-one individuals with lower limb prostheses and an expert panel assessed the content validity of the integrated items and identified 17 items. Patients who had undergone lower limb surgeries were regarded as inactive individuals, and 112 patients completed the questionnaire twice for test-retest reliability and wore an accelerometer for criterion validity. The ethics committee of Kyushu University approved this study (2019-126 and 2019-273). [Results] Item analysis was revised to the Sedentary Behavior and Light-Intensity Physical Activity Questionnaire-10 (six light-intensity physical activity and four sedentary behavior items) because of the floor effect. The test-retest correlation coefficient showed high reliability. Moderate to weak correlation coefficient was observed between the questionnaire and accelerometer (light-intensity physical activity: 0.43 and sedentary behavior: 0.20 ), and the Bland-Altman plots indicated no bias. [Conclusion] The Sedentary Behavior and Light-Intensity Physical Activity Questionnaire-10 had acceptable validity and reliability among inactive individuals and it could be used for studying light-intensity physical activity.

Key words: Physical activity, Sedentary, Validity
\end{abstract}

(This article was submitted Sep. 24, 2020, and was accepted Nov. 2, 2020)

\section{INTRODUCTION}

Physical activity is classified into three categories depending on the intensity of the activity: sedentary behavior, lightintensity physical activity, and moderate- to vigorous-intensity physical activity (MVPA) ${ }^{1)}$. There is strong evidence of an association between MVPA and health benefits ${ }^{2}$. However, some people have factors, such as health problems, feeling tired, and lacking motivation, that prevent them from participating in physical activity ${ }^{3)}$ and people with mobility limitations were found to be more sedentary than those without ${ }^{4}$. Long-term sedentary behavior causes muscle weakness, metabolic dysfunction, cardiovascular disease ${ }^{5,6)}$, and increased mortality ${ }^{7}$.

The focus of physical activity health benefits has expanded to include light-intensity physical activity, which is easy to conduct even for people who face barriers to physical activity. In recent years, several studies have revealed that light-

*Corresponding author. Kimie Fujita (E-mail: fujitak@hs.med.kyushu-u.ac.jp)

(C2021 The Society of Physical Therapy Science. Published by IPEC Inc.

(c) (1) $\odot$ This is an open-access article distributed under the terms of the Creative Commons Attribution Non-Commercial No DerivaCC BY NC ND tives (by-nc-nd) License. (CC-BY-NC-ND 4.0: https://creativecommons.org/licenses/by-nc-nd/4.0/) 
intensity physical activity has a positive effect not only physically, by preventing non-communicable diseases and improving lipid and glucose metabolism ${ }^{8}$, but also psychosocially, by decreasing depression ${ }^{9}$. Furthermore, light-intensity physical activity decreases the risk of physiological indicators such as the number of co-morbidities ${ }^{10)}$. Three hundred minutes per week of light-intensity physical activity is recommended ${ }^{11)}$.

Although most light-intensity physical activity studies used accelerometers ${ }^{8,12-14)}$, these devices needed to be worn continuously, which sometimes resulted in a high attrition rate ${ }^{15)}$. A questionnaire is a suitable measurement method for a large sample survey as it is inexpensive and versatile ${ }^{16)}$. Only two scales have focused on light-intensity physical activity measurements to date. The 7-day Sedentary and Light Intensity Physical Activity Log was the first scale developed for evaluating light-intensity physical activity and sedentary behavior ${ }^{17)}$; however, its adaptability to middle-aged and older people has not yet been established because the mean age of survey participants was 26.5 years. Second, the Community Health Activities Model Program for Seniors, a self-report scale developed as a physical activity measurement scale for older individuals, has recently been modified to measure light-intensity physical activity ${ }^{18,19)}$ but was found to have low validity. A systematic review reported that scales to measure physical activity included a limited number of light-intensity physical activity ${ }^{20)}$, and validity and/or reliability of these scales was only tested in the general population not in physically inactive people ${ }^{21-23)}$.

Patients with lower limb arthroplasty have lower levels of physical activity than individuals in the general population, even long after surgery ${ }^{24,25}$, and could be regarded as inactive people. We aimed to develop a questionnaire to characterize sedentary or light-intensity physical activity and to examine its reliability and validity in middle-aged and older adults who tend to have an inactive lifestyle.

\section{PARTICIPANTS AND METHODS}

To develop the Sedentary Behavior and Light-Intensity Physical Activity Questionnaire (SLPAQ), we extracted 265 light-intensity physical activity and sedentary behavior items from the 2011 Compendium of Physical Activities (Japanese version $)^{26)}$. It contains common activities converted into metabolic equivalent units (METs) ${ }^{26,27)}$. Then, a panel of experts, comprising physical activity researchers, clinical nurses, and orthopedic surgeons, chose 163 activities that were thought to be performed by inactive adults out of the 265 light-intensity and sedentary activities.

To identify additional activities, we conducted a review of literature on physical activity scales. We identified 25 lightintensity and sedentary activities from 22 studies. To identify any unreported physical activity items in community-dwelling middle-aged and older persons, we recruited a convenience sample of 11 community-dwelling persons 40-90 years old (age: $65.8 \pm 13.5$ years; 6 males and 5 females) who did not exercise regularly. We interviewed the participants regarding their activities over the previous 4 days. We identified 18 additional activities from this survey. The expert panel grouped the 206 activities by similarity into 58 items, comprising five domains: housework, leisure, work, transport, and self-care.

To confirm the questionnaire's content validity - its ability to capture activities that accurately represent sedentary behavior and light-intensity physical activity—we recruited patients with artificial lower limb joints from Kyushu University Hospital and expert panel members from the previous survey. We asked 31 community-dwelling outpatients aged 40 years or older with artificial lower limbs joints (age: $68.3 \pm 12.9$ years; 14 males and 17 females) to report how often they performed each of the 58 activities using a 4-point Likert scale, ranging from 1 (very infrequent) to 4 (very frequent). Items for which $>50 \%$ of responses reported 4 (very frequent) were included in the draft version of the scale. Then, 7 expert panel members participated in an item content validity index survey, using a 4-point Likert scale ranging from 1 (not relevant) to 4 (very relevant), and a content validity ratio survey, using a 3-point Likert scale ranging from 1 (not necessary) to 3 (essential) ${ }^{28}$. We used an item content validity index cut-off point of 0.8 and a content validity ratio cut-off point of 0.99 , where a value greater than the cut-off indicated acceptable validity ${ }^{29)}$. Of 58 items, 17 activity items were retained - the SLPAQ-17.

The SLPAQ-17 asked the frequency that each physical activity had been performed in the previous week and the duration of each physical activity per day; the total time spent on light-intensity physical activity and sedentary behavior per week could then be calculated. Item responses for activity duration had five categorical options (the algorithm conversion values are included in parentheses): $<1 \mathrm{~h}(0.5 \mathrm{~h}), 1-2.5 \mathrm{~h}(1.75 \mathrm{~h}), 3-4.5 \mathrm{~h}(3.75 \mathrm{~h}), 5-6.5 \mathrm{~h}(5.75 \mathrm{~h}),>7 \mathrm{~h}(7.75 \mathrm{~h})$. For activities typically performed for longer durations (e.g., lying down or sitting down), items used the same format with eight categories: $<1$ h (0.5 h), 1-2.5 h (1.75 h), 3-4.5 h (3.75 h), 5-6.5 h (5.75 h), 7-8.5 h (7.75 h), 9-10.5 h (9.75 h), 11-12.5 h (11.75 h), $>13 \mathrm{~h}(13.75 \mathrm{~h})$.

We compared the performance reliability of two new and conventional physical activity monitoring accelerometers, the Active style PRO HJA-750 (Omron Healthcare Co., Ltd., Kyoto, Japan ${ }^{30)}$ ) and Lifecorder (Suzuken Co., Ltd., Nagoya, Japan). Active style PRO captures physical activity and classifies it into walking physical activity and non-walking physical activity $^{30}$ ). We recruited 22 individuals (age: $57.6 \pm 17.4$ years; 13 males and 9 females; BMI $22.0 \pm 2.8 \mathrm{~kg} / \mathrm{m}^{2}$ ) from the general population. After the individuals were informed about the study, those who agreed to participate provided signed consent forms. Each was asked to simultaneously wear an Active style PRO accelerometer and a Lifecorder accelerometer. The intraclass correlation coefficient (ICC) for Active style PRO walking activity detection and Lifecorder physical activity detection were 0.71 for light-intensity physical activity and 0.79 for MVPA.

To test the validity and reliability of the SLPAQ-17, we selected the Active style PRO accelerometer because it was more sensitive to light-intensity physical activity than the Lifecorder accelerometer, which tended to underestimate non-walking 
activities $^{31,32)}$ such as standing, sitting while doing laundry, or dishwashing ${ }^{33)}$. Active style PRO captured these light-intensity physical activities and correctly classified them as non-walking.

To test the validity and reliability of the SLPAQ-17, patients with lower limb arthroplasty were recruited from Kyushu University Hospital. Participants who had undergone hip or/and knee arthroplasty $\geq 6$ months prior and who were aged between 40 and 90 years were eligible. The planned sample size was 100 participants, in accordance with Consensus-based Standards for the Selection of Health Measurement Instruments ${ }^{34)}$. Eligible outpatients who consented to participate were given two copies of the SLPAQ-17 questionnaire and an Active style PRO accelerometer. The participants were asked to complete the questionnaire (Time 1) and wear the accelerometer for 4 days, except while sleeping. The test-retest reliability of the questionnaire survey was conducted 1 week after the Time 1 survey (Time 2). The questionnaires and accelerometer were returned by mail. Data from those who wore the accelerometer $\geq 10 \mathrm{~h} /$ day for at least 4 days were included in the analysis ${ }^{8)}$. Physical activity intensities were defined as follows: 0.9 MET $<$ sedentary $\leq 1.5$ METs, $1.5<$ light intensity $\leq 3$ METs, and MVPA>3 METs.

Item analyses assessed ceiling and floor effects of the scale items. When $>15 \%$ of participants had the highest possible value $(>7$ or $>13 \mathrm{~h} \times 7$ days $)$ or the lowest possible value $(0 \mathrm{~h} \times 7$ days $)$, the ceiling or floor effect, respectively, was considered to be present.

Test-retest reliability was assessed using Spearman rank correlation coefficients $(\rho)$ and ICCs between Time 1 and Time 2 SLPAQ variable. Spearman rank correlation and Bland-Altman analyses of SLPAQ and accelerometer-based results (h/day) were used to evaluate item content validity. For testing proportional biases, Pearson correlation of the differences between and averages of the activity durations estimated by the accelerometer and SLPAQ were calculated. Correlation coefficients (Spearman $\rho$, Pearson and ICC) were calculated using SPSS version 24 (IBM Corp, Armonk, NY, USA), and Bland-Altman analyses were performed in Excel (Microsoft Inc). The level of significance for all statistics was set at $p<0.05$. This study was approved by the ethics committee of Kyushu University (first SLPAQ version: 2019-126; validation and reliability study: 2019-273).

\section{RESULTS}

Overall, 138 patients were asked to participate in the survey. Of these, 13 declined to participate. The response rate for the SLPAQ-17 was $96.8 \%$. Out of 121 respondents, 9 failed to wear the accelerometer. The remaining 112 patients participated in the validation study. The mean age of the participants was $67.5 \pm 10.6$ years, and 79 were female. The mean BMI was $24.5 \pm 3.9 \mathrm{~kg} / \mathrm{m}^{2}$, and most participants had undergone total hip arthroplasty $(\mathrm{n}=100,89.3 \%)$. All participants had received non-cemented prostheses. The mean number of steps was 4,644 $\pm 3,187$ steps/day. The mean durations of MVPA, lightintensity physical activity, and sedentary behavior were $0.9 \pm 0.5 \mathrm{~h} /$ day, $4.9 \pm 1.6 \mathrm{~h} /$ day, and $6.6 \pm 1.8 \mathrm{~h} /$ day, respectively. The proportions of MVPA, light-intensity physical activity, and sedentary behavior were $7.3 \%, 39.6 \%$, and $53.1 \%$, respectively.

No ceiling effect was observed, while a floor effect was demonstrated for 11 items. Of these 11 items, 2 work and 2 transport activity items were retained in the questionnaire because a previous study had classified physical activity in work and transportation in general people as crucial ${ }^{35)}$. These four retained items and the six items without floor effects were included in the final version of the questionnaire, SLPAQ-10 (Table 1), comprising six light-intensity physical activity and four sedentary behavior items.

Table 2 shows test-retest reliability and correlations between Time 1 and Time 2 of the SLPAQ-10 data. Time 1 and Time 2 showed high correlations for light-intensity physical activity items $(\rho=0.74, p<0.01)$ and moderate correlation for sedentary

Table 1. Physical activity measures derived from Time 1 survey using the SLPAQ (h/day)

$(\mathrm{n}=112)$

\begin{tabular}{|c|c|c|c|c|}
\hline Items & & Mean \pm SD & $\begin{array}{c}\text { Ceiling effect } \\
(\%)\end{array}$ & $\begin{array}{c}\text { Floor effect } \\
(\%)\end{array}$ \\
\hline \multirow[t]{2}{*}{ Housework } & Preparing and clearing meals ${ }^{\dagger}$ & $2.2 \pm 1.8$ & 0.0 & 7.1 \\
\hline & Cleaning up ${ }^{\dagger}$ & $0.7 \pm 0.8$ & 0.0 & 13.4 \\
\hline Leisure & Lying down or sitting down & $4.1 \pm 3.2$ & 5.4 & 0.0 \\
\hline \multirow[t]{2}{*}{ Work } & Sitting at work ${ }^{\ddagger}$ & $1.0 \pm 2.1$ & 0.0 & 67.9 \\
\hline & Standing or walking slowly at work ${ }^{\dagger}$ & $0.8 \pm 1.9$ & 0.0 & 78.6 \\
\hline \multirow[t]{2}{*}{ Transport } & Transporting to destination ${ }^{\dagger}$ & $0.7 \pm 1.1$ & 0.0 & 33.0 \\
\hline & Sitting in a vehicle: & $0.3 \pm 0.6$ & 0.0 & 52.7 \\
\hline \multirow[t]{3}{*}{ Self-care } & Eating meals ${ }^{\ddagger}$ & $1.2 \pm 0.8$ & 0.0 & 4.5 \\
\hline & Morning preparation ${ }^{\dagger}$ & $0.7 \pm 0.5$ & 0.0 & 0.0 \\
\hline & Preparation and tidying up before going to sleep ${ }^{\dagger}$ & $0.4 \pm 0.2$ & 0.0 & 9.8 \\
\hline
\end{tabular}

SLPAQ: Sedentary Behavior and Light Intensity Physical Activity Questionnaire; SD: standard deviation; Ceiling and floor effect: the percentage of the people scoring highest (more than 7 or 13 hours $\times 7$ days) or lowest ( 0 hours $\times 7$ days) respectively, ${ }^{\dagger}$ Light intensity physical activity, ${ }^{\star}$ Sedentary behavior. 
Table 2. Reliability of the SLPAQ-10 administered at Time 1 and Time 2 and validity coefficients for the SLPAQ-10 and accelerometer

$(\mathrm{n}=112)$

\begin{tabular}{lcccccc}
\hline & \multicolumn{3}{c}{$\begin{array}{c}\text { Reliability: the correlation between Time 1 } \\
\text { and Time 2 of the SLPAQ }\end{array}$} & \multicolumn{4}{c}{$\begin{array}{c}\text { Validity: the correlation between Accelerometer } \\
\text { physical activity and the SLPAQ }\end{array}$} \\
\cline { 2 - 7 } & Spearman's $\rho$ & $\mathrm{p}$ value & ICC & Spearman's $\rho$ & $\mathrm{p}$ value & ICC \\
\hline Light-intensity physical activity & 0.74 & $<0.01$ & 0.70 & 0.43 & $<0.01$ & 0.32 \\
Sedentary behavior & 0.66 & $<0.01$ & 0.69 & 0.20 & 0.03 & 0.10 \\
\hline
\end{tabular}

SLPAQ: Sedentary Behavior and Light Intensity Physical Activity Questionnaire; Spearman's $\rho$ : Spearman's rank correlation coefficient; ICC: Intraclass Correlation Coefficient.

behavior items $(\rho=0.66, p<0.01)$. There was also high to moderate agreement for light-intensity physical activity $($ ICC $=0.70)$ and sedentary behavior $(\mathrm{ICC}=0.69)$.

Table 2 reports Spearman $\rho$ for the SLPAQ-10 and accelerometer variables. A moderate and significant correlation between the SLPAQ-10 and light-intensity physical activity accelerometer variables $(\rho=0.43, p<0.01)$ was observed. Correlation values for SLPAQ-10 and sedentary behavior accelerometer variables were low $(\rho=0.20, p=0.03)$. Bland-Altman plots demonstrated that zero was within the $95 \%$ confidence interval (CI) of the mean difference between SLPAQ-based light-intensity physical activity (mean difference; $95 \% \mathrm{CI}=0.51 ;-0.10$ to $1.12 \mathrm{~h}$ /day) and sedentary behavior (mean difference; $95 \% \mathrm{CI}=0.10 ;-0.76$ to $0.79 \mathrm{~h}$ /day) and the accelerometer variables, indicating no bias (Fig. 1). Pearson correlation coefficients for differences and averages of the accelerometer and the SLPAQ-10 variable were $0.69(\mathrm{p}<0.01)$ and $0.64(\mathrm{p}<0.01)$ for light-intensity physical activity and sedentary behavior, respectively.

\section{DISCUSSION}

We developed a self-report questionnaire - SLPAQ-10 — to measure sedentary behavior and light-intensity physical activity among middle-age and older adults who had undergone lower limb arthroplasty and who mainly perform low-intensity activities. The current validation study showed the SLPAQ-10 had good reliability and validity compared with an accelerometer.

The SLPAQ-10 has some advantages over previous scales used to measure physical activity. First, the SLPAQ-10 had a high validity for light-intensity physical activity, while a systematic review found that most scales measuring physical activity that include light-intensity physical activity have a low validity for light-intensity physical activity ${ }^{20)}$. Second, the SLPAQ-10 is short and easy to complete; this study had a high response rate. Conversely, many physical activity scales require that participants report activity times in detail ${ }^{17,21,36)}$, which places a time burden on the participants.

Although there are light-intensity physical activity studies using accelerometers ${ }^{8,12-14)}$, participant dropout is common because of the inconvenience of wearing an accelerometer ${ }^{15}$. For example, Matsunaga et al. researched physical activity using accelerometers and health-related quality of life using questionnaires in patients 5 years after total hip arthroplasty for; the dropout rate for physical activity measurement was $64.3 \%$ and that for the questionnaire was $43.0 \%{ }^{37)}$. The SLPAQ- 10 can be used in long-term physical activity follow-up studies.

In this study, the participants were inactive individuals because patients with lower limb arthroplasty mostly engage in light-intensity physical activity and sedentary behavior. Although previous studies of light-intensity physical activity scales involved individuals from the general population ${ }^{17,19,21-23)}$, our questionnaire could be applied to populations that find performing MVPA difficult. Meanwhile, a survey comparing the physical activity of community-dwelling adults aged $\geq 50$ years reported that participants who spend more time performing light-intensity physical activity also tend to spend more time performing MVPA $^{38)}$. The use of an additional MVPA questionnaire, such as the International Physical Activity Questionnaire $^{20)}$, to capture MVPA is recommended as a complement to the SLPAQ-10 for physical activity studies.

The importance of light-intensity physical activity in health promotion has been gaining acceptance in recent years. According to a nationwide survey in the United States, $300 \mathrm{~min} /$ week of light-intensity physical activity are recommended for older adults ${ }^{11)}$. In an accelerometer-based retrospective survey in the United States, all-cause mortality risk was reduced by $14 \%$ for every increase of $60 \mathrm{~min}$ /day of light-intensity physical activity in those who self-reported that MVPA was difficult or impossible to perform without assistance ${ }^{10}$; ; therefore, light-intensity physical activity instead can be effective for people who have difficulty performing high-intensity physical activity, and the SLPAQ-10 is useful for capturing light-intensity physical activity. In an intervention study to decrease sedentary behavior, people with rheumatoid arthritis were instructed to increase the amount of light-intensity physical activity and reported a significant decrease in sedentary behavior ${ }^{39)}$. Though this study measured sedentary behavior with an accelerometer, our questionnaire could be used in such intervention studies.

While the SLPAQ-10 had higher Spearman correlations than those demonstrated by previous scales ${ }^{20)}$, and Bland-Altman plots demonstrated that 0 was within the $95 \%$ CI, Bland-Altman plots also showed proportional biases. This indicates the SLPAQ-10 variables were higher than the accelerometer variables. Additionally, in a previous study, participants tended to over-report physical activity because of factors such as social desirability ${ }^{40)}$.

This study has a couple of limitations. Sedentary behavior measured by the SLPAQ-10 had a low correlation with that 

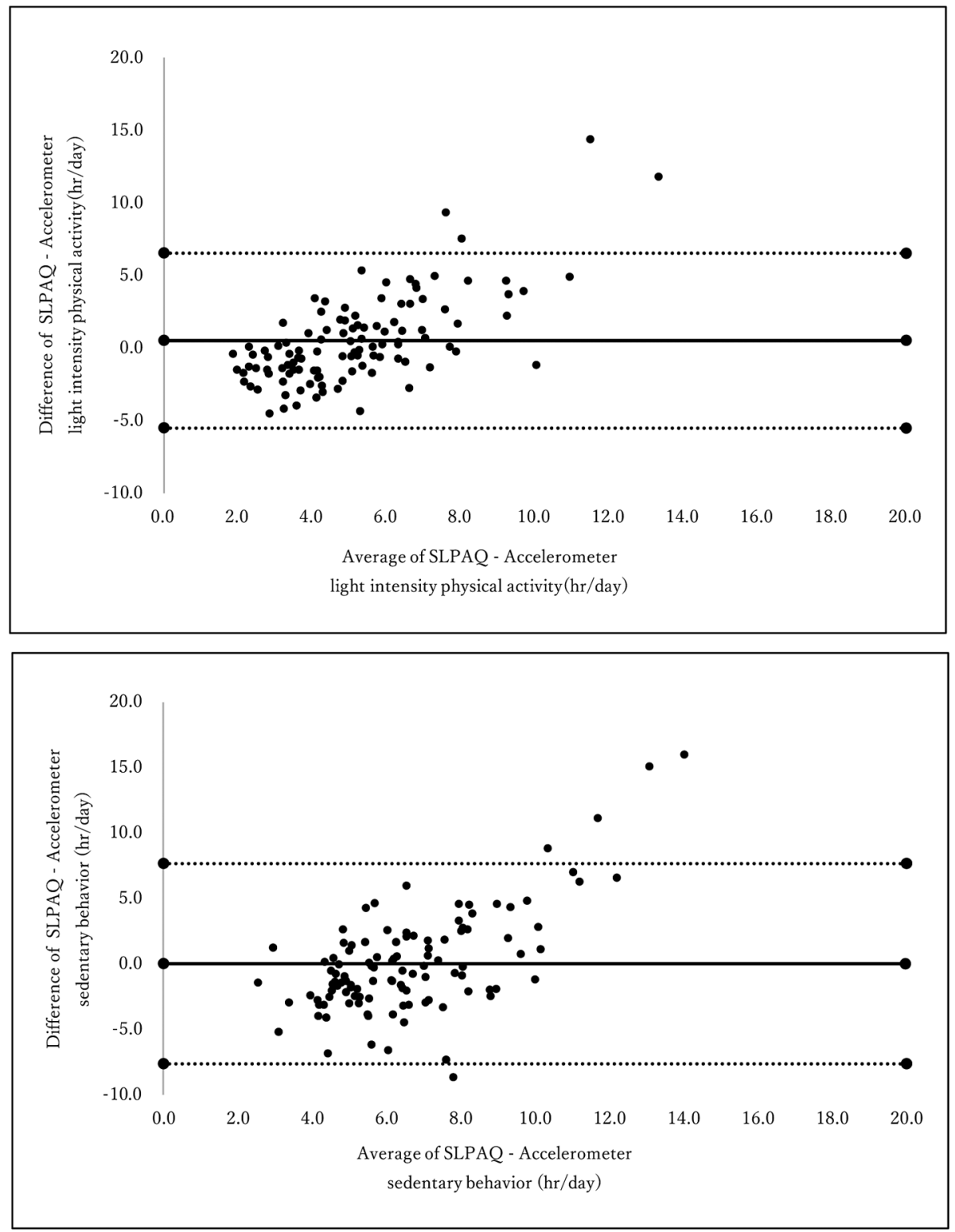

Fig. 1. Bland-Altman plots of accelerometer and Light-Intensity Physical Activity (upper panel) and Sedentary Behavior (lower panel) Questionnaire (SLPAQ) variables.

measured by the accelerometer. However, sedentary behavior scales often show no significant correlation or low correlation with accelerometer data because of factors such as excessive capture of immobilization time during sedentary behavior by the accelerometer ${ }^{20,41)}$.

The generalizability of the SLPAQ-10 to all middle-aged and older adults with an inactive lifestyle is limited because this study was based on patients who had undergone hip and/or knee total joint replacement surgery. It will be necessary to investigate the adaptability of the SLPAQ-10 to inactive people other than patients with hip or/and knee total joint replacements.

\section{Conflict of interest}

There are no conflicts of interest to declare.

\section{ACKNOWLEDGMENTS}

We are much indebted to the patients who participated in this study as well as to Satoshi Hamai, PhD; Yukio Akasaki, PhD; Hideki Mizu-uchi, PhD; Shinya Kawahara, PhD; and Hidetoshi Tsushima, MD in the Department of Orthopedic Surgery and the Nursing Department at Kyushu University Hospital. This study was funded by the Grants-in-Aid for Scientific 
Research (Grant Number Research (C) 19K11141). We thank Coren Walters-Stewart, PhD, from Edanz Group (https://enauthor-services.edanzgroup.com/ac) for editing a draft of this manuscript.

\section{REFERENCES}

1) National University of Singapore. What is MVPA? http://www.nus.edu.sg/uhc/docs/default-source/default-document-library/what-is-mvpa. pdf?sfvrsn=59cfa1de_2. (Accessed Aug. 1, 2020)

2) World Health Organization: Global recommendations on physical activity for health. Geneva: WHO Press, 2010.

3) Justine M: Barriers to participation in physical activity and exercise among middle-aged and elderly individuals. 2013, 54: 581-586.

4) Loprinzi PD, Sheffield J, Tyo BM, et al.: Accelerometer-determined physical activity, mobility disability, and health. Disabil Health J, 2014, 7: 419-425. [Medline] [CrossRef]

5) Tremblay MS, Colley RC, Saunders TJ, et al.: Physiological and health implications of a sedentary lifestyle. Appl Physiol Nutr Metab, 2010, 35: 725-740. [Medline] [CrossRef]

6) Booth FW, Roberts CK, Thyfault JP, et al.: Role of inactivity in chronic diseases: evolutionary insight and pathophysiological mechanisms. Physiol Rev, 2017, 97: 1351-1402. [Medline] [CrossRef]

7) Martinez-Gomez D, Guallar-Castillon P, Rodríguez-Artalejo F: Sitting time and mortality in older adults with disability: a national cohort study. J Am Med Dir Assoc, 2016, 17: 960.e15-960.e20. [Medline] [CrossRef]

8) Füzéki E, Engeroff T, Banzer W: Health benefits of light-intensity physical activity: a systematic review of accelerometer data of the national health and nutrition examination survey (NHANES). Sports Med, 2017, 47: 1769-1793. [Medline] [CrossRef]

9) Buman MP, Hekler EB, Haskell WL, et al.: Objective light-intensity physical activity associations with rated health in older adults. Am J Epidemiol, 2010, 172: 1155-1165. [Medline] [CrossRef]

10) Frith E, Loprinzi PD: Accelerometer-assessed light-intensity physical activity and mortality among those with mobility limitations. Disabil Health J, 2018, 11: 298-300. [Medline] [CrossRef]

11) Loprinzi PD, Lee H, Cardinal BJ: Evidence to support including lifestyle light-intensity recommendations in physical activity guidelines for older adults. Am J Health Promot, 2015, 29: 277-284. [Medline] [CrossRef]

12) Spartano NL, Davis-Plourde KL, Himali JJ, et al.: Association of accelerometer-measured light-intensity physical activity with brain volume: the Framingham heart study. JAMA Netw Open, 2019, 2: e192745. [Medline] [CrossRef]

13) Stubbs B, Chen LJ, Chang CY, et al.: Accelerometer-assessed light physical activity is protective of future cognitive ability: a longitudinal study among community dwelling older adults. Exp Gerontol, 2017, 91: 104-109. [Medline] [CrossRef]

14) Seol J, Abe T, Fujii Y, et al.: Effects of sedentary behavior and physical activity on sleep quality in older people: a cross-sectional study. Nurs Health Sci, 2020, 22: 64-71. [Medline] [CrossRef]

15) Pedišić Ž, Bauman A: Accelerometer-based measures in physical activity surveillance: current practices and issues. Br J Sports Med, 2015 , 49: 219-223. [Medline] [CrossRef]

16) Pols MA, Peeters PH, Kemper HC, et al.: Methodological aspects of physical activity assessment in epidemiological studies. Eur J Epidemiol, 1998, 14: 63-70. [Medline] [CrossRef]

17) Barwais FA, Cuddihy TF, Washington T, et al.: Development and validation of a new self-report instrument for measuring sedentary behaviors and lightintensity physical activity in adults. J Phys Act Health, 2014, 11: 1097-1104. [Medline] [CrossRef]

18) Stewart AL, Mills KM, King AC, et al.: CHAMPS Physical Activity Questionnaire for. 1989.

19) Hekler EB, Buman MP, Haskell WL, et al.: Reliability and validity of CHAMPS self-reported sedentary-to-vigorous intensity physical activity in older adults. J Phys Act Health, 2012, 9: 225-236. [Medline] [CrossRef]

20) Helmerhorst HJ, Brage S, Warren J, et al.: A systematic review of reliability and objective criterion-related validity of physical activity questionnaires. Int J Behav Nutr Phys Act, 2012, 9: 103. [Medline] [CrossRef]

21) Nicolaou M, Gademan MG, Snijder MB, et al.: Validation of the SQUASH physical activity questionnaire in a multi-ethnic population: the HELIUS study. PLoS One, 2016, 11: e0161066. [Medline] [CrossRef]

22) Strath SJ, Bassett DR Jr, Swartz AM: Comparison of the college alumnus questionnaire physical activity index with objective monitoring. Ann Epidemiol, 2004, 14: 409-415. [Medline] [CrossRef]

23) Chinapaw MJ, Slootmaker SM, Schuit AJ, et al.: 2109 Reliability and validity of the activity questionnaire for adults and adolescents (AQuAA). BMC Med Res Methodol, 2009, 9: 58. [Medline] [CrossRef]

24) King LK, Kendzerska T, Waugh EJ, et al.: Impact of osteoarthritis on difficulty walking: a population-based study. Arthritis Care Res (Hoboken), 2018, 70: 71-79. [Medline] [CrossRef]

25) Arnold JB, Walters JL, Ferrar KE: Does physical activity increase after total hip or knee arthroplasty for osteoarthritis? A systematic review. J Orthop Sports Phys Ther, 2016, 46: 431-442. [Medline] [CrossRef]

26) Ministry of Health, Labour and Welfare: Revised version of Codes and MET Values; 2012 https://www.nibiohn.go.jp/files/2011mets.pdf. (in Japanese) (Accessed Aug. 1, 2020)

27) Ainsworth BE, Haskell WL, Herrmann SD, et al.: 2011 Compendium of physical activities: a second update of codes and MET values. Med Sci Sports Exerc, 2011, 43: 1575-1581. [Medline] [CrossRef]

28) Zamanzadeh V, Ghahramanian A, Rassouli M, et al.: Design and implementation content validity study: development of an instrument for measuring patientcentered communication. J Caring Sci, 2015, 4: 165-178. [Medline] [CrossRef]

29) Davis LL: Instrument review: getting the most from a panel of experts. Appl Nurs Res, 1992, 5: 194-197. [CrossRef]

30) Ohkawara K, Oshima Y, Hikihara Y, et al.: Real-time estimation of daily physical activity intensity by a triaxial accelerometer and a gravity-removal clas- 
sification algorithm. Br J Nutr, 2011, 105: 1681-1691. [Medline] [CrossRef]

31) Hikihara Y, Tanaka S, Ohkawara K, et al.: Validation and comparison of 3 accelerometers for measuring physical activity intensity during nonlocomotive activities and locomotive movements. J Phys Act Health, 2012, 9: 935-943. [Medline] [CrossRef]

32) Matthew CE: Calibration of accelerometer output for adults. Med Sci Sports Exerc, 2005, 37: S512-S522. [Medline] [CrossRef]

33) Oshima Y, Kawaguchi K, Tanaka S, et al.: Classifying household and locomotive activities using a triaxial accelerometer. Gait Posture, 2010, 31: 370-374. [Medline] [CrossRef]

34) COSMIN: COSMIN checklist with 4-point scale. Cosmin, 2011, 6

35) Pettee Gabriel KK, Morrow JR Jr, Woolsey AL: Framework for physical activity as a complex and multidimensional behavior. J Phys Act Health, 2012, 9: S11-S18. [Medline] [CrossRef]

36) Buchowski MS, Matthews CE, Cohen SS, et al.: Evaluation of a questionnaire to assess sedentary and active behaviors in the Southern Community Cohort Study. J Phys Act Health, 2012, 9: 765-775. [Medline] [CrossRef]

37) Matsunaga-Myoji Y, Fujita K, Makimoto K, et al.: Three-year follow-up study of physical activity, physical function, and health-related quality of life after total hip arthroplasty. J Arthroplasty, 2020, 35: 198-203. [Medline] [CrossRef]

38) Blodgett J, Theou O, Kirkland S, et al.: The association between sedentary behaviour, moderate-vigorous physical activity and frailty in NHANES cohorts. Maturitas, 2015, 80: 187-191. [Medline] [CrossRef]

39) Thomsen T, Aadahl M, Beyer N, et al.: Sustained long-term efficacy of motivational counselling and text message reminders on daily sitting time in patients with rheumatoid arthritis? Long-term follow-up of a randomized, parallel-group trial. Arthritis Care Res (Hoboken), $2019,0-2$.

40) Adams SA, Matthews CE, Ebbeling CB, et al.: The effect of social desirability and social approval on self-reports of physical activity. Am J Epidemiol, 2005, 161: 389-398. [Medline] [CrossRef]

41) Van Cauwenberg J, Van Holle V, De Bourdeaudhuij I, et al.: Older adults' reporting of specific sedentary behaviors: validity and reliability. BMC Public Health, 2014, 14: 734. [Medline] [CrossRef] 